\title{
Estimating radar reflectivity - snowfall rate relationships and their uncertainties over Antarctica by combining disdrometer and radar observations
}

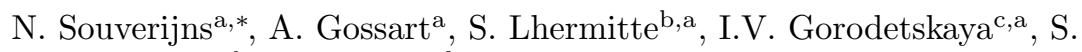 \\ Kneifel $^{\mathrm{d}}$, M. Maahn ${ }^{\mathrm{e}, \mathrm{f}}$, F.L. Bliven ${ }^{\mathrm{g}}$, N.P.M. van Lipziga ${ }^{\mathrm{a}}$ \\ ${ }^{a}$ Department of Earth and Environmental Sciences, KU Leuven, Belgium \\ ${ }^{b}$ Department of Geoscience and Remote Sensing, Delft University of Technology, The \\ Netherlands \\ ${ }^{c}$ CESAM - Centre for Environmental and Marine Studies, Department of Physics, \\ University of Aveiro, Portugal \\ ${ }^{d}$ Institute for Geophysics and Meteorology, University of Cologne, Germany \\ ${ }^{e}$ Cooperative Institute for Research in Environmental Sciences, University of Colorado, \\ Boulder, CO, USA \\ ${ }^{f}$ NOAA Earth System Research Laboratory, Boulder, CO, USA \\ ${ }^{g}$ NASA GSFC/Wallops Flight Facility, Wallops Island, VA, USA
}

\begin{abstract}
Snowfall rate (SR) estimates over Antarctica are sparse and characterised by large uncertainties. Yet, observations by precipitation radar offer the potential to get better insight in Antarctic SR. Relations between radar reflectivity (Ze) and snowfall rate (Ze-SR relations) are however not available over Antarctica. Here, we analyse observations from the first Micro Rain Radar (MRR) in Antarctica together with an optical disdrometer (Precipitation Imaging Package; PIP), deployed at the Princess Elisabeth station. The relation $\mathrm{Ze}=\mathrm{A}^{*} \mathrm{SR}^{\mathrm{B}}$ was derived using PIP observations and its uncertainty was quantified using a bootstrapping approach, randomly sampling within the range of uncertainty. This uncertainty was used to assess the uncertainty in snowfall rates derived by the MRR. We find a value of $\mathrm{A}=18$ [11-43] and $\mathrm{B}=1.10$ [0.97-1.17]. The uncertainty on snowfall rates of the MRR based on the Ze-SR relation are limited to $40 \%$, due to the propagation of uncertainty in both Ze as well as SR,
\end{abstract}

\footnotetext{
${ }^{*}$ Corresponding author at: Department of Earth and Environmental Sciences, KU Leuven, Celestijnenlaan 200E, 3001 Heverlee, Belgium

Email address: niels.souverijns@kuleuven.be (N. Souverijns)
}

Preprint submitted to Atmospheric Research

June 23, 2017 
resulting in some compensation. The prefactor (A) of the Ze-SR relation is sensitive to the median diameter of the snow particles. Larger particles, typically found closer to the coast, lead to an increase of the value of the prefactor (A $=44$ ). Smaller particles, typical of more inland locations, obtain lower values for the prefactor $(\mathrm{A}=7)$. The exponent $(\mathrm{B})$ of the Ze-SR relation is insensitive to the median diameter of the snow particles. In contrast with previous studies for various locations, shape uncertainty is not the main source of uncertainty of the Ze-SR relation. Parameter uncertainty is found to be the most dominant term, mainly driven by the uncertainty in mass-size relation of different snow particles. Uncertainties on the snow particle size distribution are negligible in this study as they are directly measured. Future research aiming at reducing the uncertainty of Ze-SR relations should therefore focus on obtaining reliable estimates of the mass-size relations of snow particles.

Keywords: Antarctica, disdrometer, snowfall rate, radar, uncertainty quantification

2010 MSC: $86 \mathrm{~A} 10$

\section{Introduction}

The Antarctic Ice Sheet (AIS) is the largest ice body on earth, having a volume equivalent to $58.3 \mathrm{~m}$ global mean sea level rise (Vaughan et al., 2013). In order to understand future changes regarding the mass of the AIS and its 5 impact on sea level rise, information on present-day precipitation amounts is indispensable (Bromwich et al., 2004: Genthon et al., 2009, Palerme et al., 2017). Precipitation is the dominant source term in the surface mass balance of the AIS. However, this quantity is not well constrained in both models and observations (Bromwich et al., 2004 Palerme et al. 2014). Most climate models have physics that are not adapted for the Antarctic climate, leading to high biases compared to local observations or reanalysis products (Agosta et al., 2015). Direct observations over the AIS are also not coherent, as they are sparse in space and time and since acquisition techniques differ. These records are usually determined 
from ice cores, satellite products or stake measurements. Observations are often disturbed by blowing snow, which makes the distinction between transported and precipitating snow impossible (Knuth et al., 2010). This also impedes the use of precipitation gauges over Antarctica, as blowing snow may enter the gauge, while high wind speeds may lead to an undercatchment of precipitation (Yang et al. 1999). As a result, precipitation observations stay mostly limited 20 to continent-wide averages (e.g. Vaughan et al., 1999).

One potential technique to constrain precipitation involves the use of a radar, ¡which has been demonstrated to effectively detect frozen precipitation (Matrosov et al., 2008). Radar-based methods often use power-law relations between the measured equivalent radar reflectivity factor $\left(\mathrm{Ze}\right.$ or $\mathrm{Z}=10 \log _{10}\left(\mathrm{Ze} / \mathrm{Ze}_{0}\right)$, 25 where $\mathrm{Ze}_{0}=1 \mathrm{~mm}^{6} \mathrm{~m}^{-3}$ ) and the melted liquid equivalent snowfall rate (SR) (Sekhon and Srivastava, 1970, Battan, 1973). Several authors have derived a power law $\left(\mathrm{Ze}=\mathrm{A}^{*} \mathrm{SR}^{\mathrm{B}}\right)$ for snowfall during different meteorological conditions for different locations (e.g. Rasmussen et al., 2003, Matrosov, 2007; Kulie and Bennartz, 2009). Matrosov et al. (2009) states that characteristic values of the exponent $\mathrm{B}$ for dry snowfall relations are generally in the range $1.3-1.55$ (when $\mathrm{Z}$ is in $\mathrm{dBz}$ and $\mathrm{SR}$ is in $\mathrm{mmh}^{-1}$ ). The prefactor A exhibits stronger variability and its range varies from about 30 (for aircraft-based size distributions and smaller density particles) to 140 (for surface-based size distributions) (Matrosov et al. 2009). It must be noted that these relations depend on snowflake 35 characteristics which can show large spatial and temporal variations. Therefore, information about the physical properties of the snowflakes needs to be known in order to derive Ze-SR relations. e.g. shape, diameter, particle size distribution (PSD), terminal fall velocity and mass (or density).

A variety of interrelated snowflake characteristics are important when con40 verting $\mathrm{Z}$ into SR (Huang et al. 2015). Mass and terminal fall velocity both depend on the shape of the particle and the range of variability of different relations can be several orders of magnitude (e.g. Locatelli and Hobbs, 1974 . Mitchell et al. 1990, Brown and Francis, 1995, Brandes et al., 2008, Heymsfield and Westbrook, 2010). This also implies that the uncertainty of the Ze-SR is of 
45 a much higher magnitude than for liquid precipitation (where the dependence of terminal fall velocity or drop mass is better constrained) (Matrosov, 2007. Matrosov et al. 2009).

Ze depends on $\mathrm{E}\left[\sim \mathrm{m}(\mathrm{D})^{2}\right]$ where $\mathrm{m}$ denotes the particle mass and $\mathrm{E}$ stands for the expected value which we integrated over the size distribution (Field

50 et al. 2005: Hogan and Westbrook, 2014). SR depends on $\mathrm{E}[\mathrm{v}(\mathrm{D}) \mathrm{m}(\mathrm{D})]$, where $\mathrm{V}^{\mathrm{V}}$ is the terminal fall velocity of the particle (Matrosov et al., 2008, Huang et al. 2015). Understanding how these uncertainties behave remains however a paramount question (Berne and Krajewski, 2013).

In order to constrain the uncertainty of the Ze-SR relation, information about the microphysical structure of the snowflakes is needed (Wood et al. 2015). In the early years, these characteristics were obtained by capturing individual snow particles e.g. on a glass plate covered with oil or a petri dish to derive its shape and mass (Nakaya and Terada, 1935; Kajikawa, 1972, Mitchell et al., 1990), while terminal fall velocities were recorded by manual timing Nakaya and Terada, 1935) or by detecting disturbances in light beams (Locatelli and Hobbs, 1974). The disadvantage of these methods is their labour intensity. During the last decades, video disdrometers are used as the standard to estimate snow microphysical properties and to obtain information on „snowflake size spectra (e.g. Brandes et al., 2007, Huang et al., 2010; Szyrmer and

65 Zawadzki, 2010, Zhang et al., 2011; Huang et al., 2015). These instruments have the advantage to capture large samples at high resolution for longer time-spans (Brandes et al., 2007, Wood et al., 2013).

Antarctica has a unique precipitation climate as accumulation is composed of few large snowfall events. These storms are often associated with atmospheric rivers bringing moisture from mid-latitudes to inland regions (Gorodetskaya et al. 2014). Therefore, the main goal of the paper is to derive a Ze-SR relation that takes into account the specific conditions of this region. This relation can then be used to transform radar reflectivity measurements obtained by precipitation radars into snowfall rates. Gorodetskaya et al. (2015) used for the first 75 time in Antarctica radar-derived snowfall estimates in order to assess relative 
contribution of precipitation to the surface mass balance compared to other components. Applying a range of Ze-SR relationships for dry snow, significant uncertainties were found especially for intense precipitation events. Here we show that adding snow particle microphysical measurements to the radar substantially reduce this uncertainty. Furthermore, a large part of the paper focuses on obtaining a rational estimate of the uncertainty of Ze, SR and the Ze-SR relation at the Princess Elisabeth station in Dronning Maud Land, East Antarctica for the first time. First, an overview of the instrumentation used in the study is presented. Next, we focus on the particle characteristics that are used as input for Ze and SR estimates based on disdrometer measurements. Here, every term is discussed separately and a rational estimate of their uncertainties is calculated. These are subsequently used to calculate the Ze-SR relation and its uncertainty. The uncertainty is subdivided in different terms regarding their nature. Finally, the applicability of this relation and its uncertainty estimate for the Antarctic region are discussed.

\section{Material and methods}

\subsection{Instrumentation}

Long-term direct and reliable measurements of meteorological conditions over the AIS are scarce due to its harsh physical environment and difficult accessibility. To tackle this problem, in 2009, a limited-maintenance atmospheric observatory was installed on the zero-emission Princess Elisabeth station in the escarpment zone of the East Antarctic plateau (71 ${ }^{\circ} 57^{\prime} \mathrm{S}, 23^{\circ} 21^{\prime} \mathrm{E} ; 1392 \mathrm{~m}$ a.m.s.l., $173 \mathrm{~km}$ from the coast) in Dronning Maud Land, north of the Sør Rondane mountain chain on Utsteinen ridge (a detailed description of the site can be found in Gorodetskaya et al. (2013)). Z measurements are recorded since 2010 by use of a vertically pointing Micro Rain Radar-2 (MRR) operating at a frequency of $24 \mathrm{GHz}$ (Klugmann et al., 1996). Although the MRR was originally designed for the detection of liquid rain, the potential of millimeter radars to efficiently detect snowfall was demonstrated by Matrosov et al. (2008) and 
Berne and Krajewski (2013) and has been evaluated specifically for our type of low-cost radar by Kneifel et al. (2011). Furthermore, the standard postprocessing method has a lower bound sensitivity of approximately $+3 \mathrm{dBz}$. This would imply that light snowfall events, which are common over inland Antarctica (Gorodetskaya et al. 2015), would be missed. Therefore, the operational MRR procedures to derive standard radar variables like $\mathrm{Z}$ or Doppler velocity were modified for snowfall. A new method, developed by Maahn and Kollias (2012), was applied to fully exploit the MRR hardware in case of solid precipitation, increasing its sensitivity up to -14 and $-8 \mathrm{dBz}$, depending on vertical range.

The development of a Ze-SR relation requires information of snow particle microphysical characteristics. In order to bridge this gap, a Precipitation Imaging Package (PIP; Newman et al. (2009)) was installed at the station in January 2016, which operated until the end of May 2016. The field unit consists of a video system inside a heated housing, plus a halogen lamp that is located 3 $\mathrm{m}$ from the camera. The PIP is setup at the edge of the roof of the Princess Elisabeth station, towards the upstream side of the dominant wind direction (Fig. 1). The optical axis is oriented perpendicular to the climatological mean wind, as suggested by Newman et al. (2009). The field of view of the camera is $640 \times 480$ pixels, while the depth of field equals approximately 60 times the 125 particle diameter (Newman et al. 2009). Pixel size accords to $0.1 \mathrm{~mm}$. The system is connected to a datalogger which is particularly suitable for long-duration, unattended operation because the software provides data compression, while the hardware can operate for months in harsh winter conditions (Newman et al. 2009). The high speed camera takes pictures at a rate of 360 frames per second. The background of these images are white and snow particles passing between the camera and the halogen lamp are visible as grey silhouettes. In addition to storing these images, the PIP software also derives geometric parameters for every detected snowflake such as diameter, area, elliptic axis ratio, grey level, among others. Apart from these single-particle parameters, the PIP also calculates ensemble properties, such as the PSD (for every minute and averaged for 


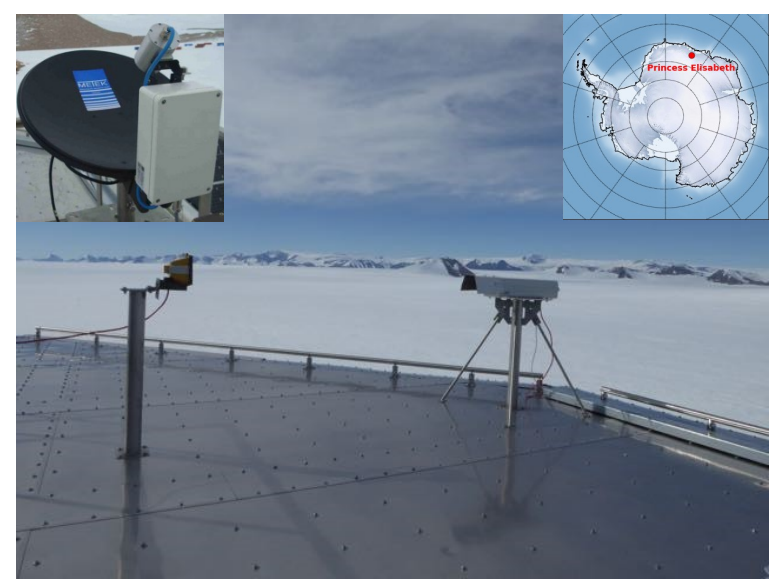

Figure 1: The PIP deployed on the roof of the Princess Elisabeth station. The camera is located in the heated housing on the right of the image, while the halogen lamp is on the left. The upper left inset shows the MRR, while the upper right inset shows the location of the Princess Elisabeth station.

an entire snow storm). Furthermore, a built-in tracker algorithm identifies the movement of snow particles throughout different image frames. In case a match is found, it allows to calculate the terminal fall velocity of the particle. At the same time, this algorithm avoids doubling counting of particles.

\section{2. $M R R$ data processing}

The MRR was configured to operate in the range of 300 up to $3000 \mathrm{~m}$ a.g.l. having a vertical resolution of $100 \mathrm{~m}$. This implies that precipitation is not measured in the lowest atmospheric levels $(0-300 \mathrm{~m})$. As the MRR often detects virga (snowfall sublimating in its fall streak), it is very probable sublimation also takes place in these levels below $300 \mathrm{~m}$, leading to an overestimation of SR (Maahn et al., 2014). Furthermore, high wind speeds can also horizontally displace falling snow particles before they reach the surface. In order to tackle this problem, the height correction of Wood (2011) is applied to the MRR data, by extrapolating the trend in the lowest MRR vertical levels towards the surface to account for horizontal displacement and sublimation below the 
lowest measurement level. This results, on average, in a decrease in $\mathrm{Z}$ of 1.66 $\mathrm{dBz}$ between the lowest measurement level (at $300 \mathrm{~m}$ a.g.l.) and the surface.

Further, the calibration offset of the MRR is calculated by comparing mean vertical profiles of $\mathrm{Z}$ with the space-borne cloud radar Cloudsat (Stephens et al.

1552002 ) following Protat et al. (2009, 2010). A mean offset of $+1.13 \mathrm{dBz}$ is found which is applied on all measurements obtained by the MRR. This offset is relatively small compared to other calibration studies (Protat et al., 2011).

The uncertainty of the measured $\mathrm{Z}$ of the MRR were not calculated directly, but a thorough discussion of the total error structure of radars can be found in 160 Villarini and Krajewski (2010) and Berne and Krajewski (2013).

\subsection{Disdrometer reflectivity and snowfall rate}

Combining radar and disdrometer results has shown to be very successful in obtaining estimates of SR (Huang et al. 2010, Zhang et al., 2011, Wood et al. 2014, Huang et al. 2015). Using the different data products obtained by the $165 \mathrm{PIP}$, it is possible to calculate the Ze:

$$
Z e=10^{18} \frac{\lambda}{\pi^{5}|K|^{2}} \int_{D_{\min }}^{D_{\max }} \sigma_{b}(D) N(D) d D
$$

Here, Ze has units $\mathrm{mm}^{6} \mathrm{~m}^{-3}, \lambda$ is the MRR wavelength in $\mathrm{m},|\mathrm{K}|^{2}$ is related to the dielectric constant of liquid water and conventionally equals 0.92 (Battan, 1973: Atlas et al., 1995), $\sigma_{D}$ is the backscatter cross section diameter relation in $\mathrm{m}^{2}$ and $\mathrm{N}(\mathrm{D})$ is the particle size distribution in $\mathrm{m}^{-4}$. The diameters observed 170 by the PIP are constrained between $200 \mu \mathrm{m}\left(\mathrm{D}_{\min }\right)$ and $25 \mathrm{~mm}\left(\mathrm{D}_{\max }\right)$ and are binned in size categories with a width of $200 \mu \mathrm{m}$.

Further, it is also possible to derive a SR:

$$
S R=\frac{3600}{\rho_{w}} \int_{D_{\min }}^{D_{\max }} m(D) v(D) N(D) d D
$$

In this equation, SR has units $\mathrm{mm} \mathrm{h}^{-1}, \rho_{w}$ is the density of liquid water, $\mathrm{m}(\mathrm{D})$ is the mass diameter relation, and $\mathrm{v}(\mathrm{D})$ the terminal fall velocity diameter re175 lation (all SI units). In the following subsections, each of the above parameters 
is discussed, including their uncertainty and possible pre- and postprocessing steps.

During the sampling period (January 2016 - May 2016) 24 distinct snow storms were recorded by the PIP. However, not all data can be used to derive a Ze-SR relation, since high horizontal wind speeds resulted in particles being missed by the PIP. As precipitation events mostly occur during periods with high wind speeds, a set of criteria were therefore defined which must be fulfilled in order to include (part of) the observations:

1. Maximum wind speed: based on the field of view, the depth of field, the image acquisition rate (360 frames per second) of the PIP and the corresponding wind direction during snowfall, it is possible to calculate a maximum wind speed that may not be exceeded for every wind direction. As such, it can be assured that snowflakes are detected by the PIP in at least two successive image frames. Furthermore, if wind speeds are higher than the calculated maximum during $50 \%$ of the total snow storm duration, the snow storm is rejected as a whole. Wind speed and direction data is obtained from an Automatic Weather Station, located 300 m east from the station.

2. $-5 \mathrm{dBz}$ threshold: every minute of data for which a MRR $\mathrm{Z}$ of less than $-5 \mathrm{dBz}$ is obtained, is not taken into account. Below this threshold, radar $\mathrm{Z}$ measurements of the MRR might be incomplete (Maahn and Kollias, 2012, and section 2.1.

3. Average Z: The snow storm must have an average $\mathrm{Z}$, calculated by the logarithm of Eq. 1, higher than $-5 \mathrm{dBz}$.

200

Taking these criteria into account, a total of 12 individual snow storms are available for analysis consisting of more than 120 hours of data and having MRR $\mathrm{Z}$ values ranging from -5 to $18 \mathrm{dBz}$ (Tab. S1 (Supplementary Information)). This covers the full range of $\mathrm{Z}$ values that are observed at the Princess Elisabeth station since 2010 (Gorodetskaya et al., 2015). 
order to take this variability between snow storms into account, an additional analysis was performed in which every event is considered separately in the calculation of Ze, SR and the parameters of the Ze-SR relation. 


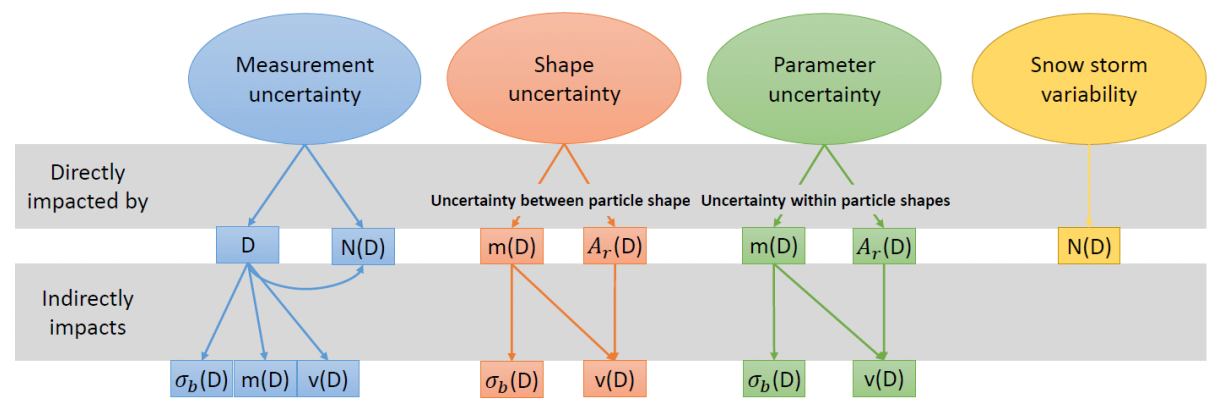

Figure 2: Overview scheme listing the four uncertainty terms and different terms contributing to each uncertainty. E.g. parameter uncertainty is directly impacted by the uncertainty of the mass of the particle for each particle shape and the area ratio, indirectly impacting the backscatter cross section and the terminal fall velocity of a snow particle, as uncertainties propagate into these parameters.

\subsubsection{Particle diameter}

Snow particles over Antarctica are generally smaller compared to other regions of the world. The largest particles are found close to the coast, where more water vapour is available and diameters up to $10 \mathrm{~mm}$ are recorded (Konishi et al. 1992). More inland stations mention snowflakes of much smaller sizes, ranging from maxima of $100 \mu \mathrm{m}$ at South Pole (Walden et al. 2003; Lawson

et al. 2006) till hundreds of $\mu \mathrm{m}$ at other inland stations (for an overview see Lachlan-Cope et al., 2001).

The diameter of a snow particle is measured in several ways by the PIP. In general, every snowflake is circumscribed by an ellipse, for which the minor and major axis lengths are stored together with its total projected area.

245 In case a particle is observed multiple times, both the average and individual measurements are stored. Furthermore, the radius of a circle with the same area as the ellipse is calculated. In order to construct the PSD, one of the above measures needs to be binned in certain size classes. Tiira et al. (2016) propose the use of the volume equivalent diameter to bin particles. However, the volume equivalent diameter is not measured directly by the PIP as we only have 2D images available. Nevertheless, from PIP measurements it is possible 
to obtain a proxy for the volume equivalent diameter (Tiira et al. 2016). Assuming spheroid particle shapes (Matrosov, 2007) and taking typical vertical aspect ratios for particles over Antarctica ranging between 0.4 and 0.8 (Korolev 255 and Isaac, 2003, Matrosov et al., 2005), we found that the volume equivalent diameter approximately equals the radius of a circle with the same area as the elliptic projection circumventing the snow particle. As such, this measure is used to bin snow particles.

Parametrisations for mass and terminal fall velocity are typically expressed in terms of the maximum dimension of the particle (e.g. Mitchell 1996); Heymsfield and Westbrook (2010); Hogan et al. (2012)). Since the PIP views a 2Dprojection of the actual particle (Löffler-Mang and Blahak, 2001), none of the dimensions discussed above can be identified as the real maximum dimension of the snow particles. Assuming the PIP binning diameter to be the maximum dimension can lead to substantial errors in Ze estimates (up to 50\%) (Wood et al. 2013). In our study, the correction of Wood et al. (2013, based on their Fig. 3a) was applied on the maximum dimension measured by the PIP, assuming vertical aspect ratios ranging between 0.4 and 0.8 . This correction involves the entire particle range needs to be transformed including the adaptation of the diameter in all parameters of Eq. 1 and 2

Despite this correction, the maximum dimension of the snow particles are still affected by other uncertainties. Newman et al. (2009) stated that errors in the measured particle size occur due to blurring or a lack of contrast in the image (i.e. analytic uncertainty). According to them, this uncertainty is normally distributed and equals $15 \%\left(10^{\text {th }}\right.$ and $90^{\text {th }}$ percentile) for spherical particles (Newman et al. 2009), which is the value used in this study. Furthermore, particles may also be missed by the PIP due to sampling errors. Sampling errors are assumed to be random and Poisson-distributed (Wood et al., 2013) and are therefore of a lower magnitude (less than 3\%) than analytic errors, decreasing towards larger particle diameters. Characterisation of the uncertainty in diameter measurements is important since these inaccuracies will propagate into all other parameters of Eq. 1 and 2 that are a function of D (Fig. 2). 


\subsubsection{Particle size distribution}

The PSD for every minute of snowfall is calculated directly by the PIP. As of around $0.5-0.8 \mathrm{~mm}$ (Gorodetskaya et al., 2015). As these measurements were 
performed during low horizontal wind speeds and low SR, only small particles were observed.

Particle shapes are not directly identified by PIP and in situ particle shape measurements were limited to a low number of particles during low wind speed conditions in summer. Therefore, uncertainty cannot be derived based on these measurements. Based on observations at other Antarctic stations, it was found that snow storms usually consist of a mixture of different pristine particle shapes together with aggregates (for an overview see Lachlan-Cope (2010)). However, Lawson et al. (2006) showed that some snow storms consist of only one specific pristine shape. Furthermore, based on observations from Dumont D'Urville and South Pole (Lawson et al., 2006), it was found that columns are observed in the smallest size bins, while largest particles are usually identified to be aggregates. 325 In order to define the uncertainty of particle shape occurrences at different sizes, particle shape occurrence probability distributions are constructed as a function of particle size for each particle shape. Based on observations from South Pole (Lawson et al. 2006) and Dumont D'Urville (pers. comm. Alexis Berne) the gamma distribution, which is usually used to fit the full PSD, is considered a good fit for these individual particle shape occurrence probability distributions. The behaviour of single particles (e.g. columns being smaller than aggregates) and its uncertainty can then be simulated by varying the two parameters describing the gamma distribution, $\mathrm{k}$ and $\theta$ :

$$
f(D, k, \theta)=\frac{1}{\Gamma(k) \theta^{k}} D^{k-1} e^{-\frac{D}{\theta}}
$$

The range of these parameters is defined in Tab. 1. As our knowledge about particle shape characteristics at Princess Elisabeth is limited and observations are limited to two Antarctic sites, the spectrum of $\mathrm{k}$ and $\theta$ values is chosen very broad allowing for a high variability in particle shape occurrence probability distributions (Fig. 3).

Pristine particles mostly occur at smallest sizes and their frequency of oc340 currence decreases towards higher size bins, as largest particles are mostly considered to be aggregates (Fig. 3). The median of their occurrence probability 


\begin{tabular}{|l|c|c|}
\hline Shape & $\mathrm{k}$ & $\theta$ \\
\hline Columns and plates & $0-12$ & $0-0.15$ \\
Rosettes & $0-12$ & $0-0.30$ \\
Dendrites and sector & $0-12$ & $0-0.30$ \\
Aggregates & $4-12$ & $0.30-0.60$ \\
\hline
\end{tabular}

Table 1: $\mathrm{k}$ and $\theta$ parameter range uncertainty for the particle type gamma distribution defining the particle shape occurrence probability distribution with respect to diameter $(\mathrm{mm})$ in Fig. 3

distribution is therefore limited to the lower limit of the particle size spectrum and to low frequencies (mixtures of pristine shapes mostly occur during the same storm; Fig. 3a). In some cases however, snow storms do consist of only small particle sizes and one particle shape (Lawson et al., 2006). By defining the $\mathrm{k}$ and $\theta$ parameter in the range of Tab. 11 these particular snow storms are also taken into account (Fig. 3a). Aggregates correspond almost always to the largest particle sizes (Fig. 3d).

In general, we can state that by randomly sampling the $\mathrm{k}$ and $\theta$ parameters from the range defined in Tab. 1, a very broad spectrum of particle shape occurrence probability distributions is obtained, falling within the range of reality.

\subsubsection{Mass}

The mass of a snow particle highly depends on the history of the particle and the environment in which it was formed, including processes such as riming and aggregation (Mitchell et al. 1990). Several authors studied the mass of snow particles with different shapes using different real-time sampling techniques during snow storms or by simulating snowflakes in lab conditions, obtaining power law relations of the form $\mathrm{m}=\alpha \mathrm{D}^{\beta}$ (e.g. Locatelli and Hobbs, 1974, Mitchell et al., 1990). These relations are characterised by a large spread even within a certain particle shape class. The mass of snowflakes is not measured by the PIP. As such, a literature study was performed documenting parametrisations for all particle shapes that were detected at the Princess Elisabeth station (Tab. 


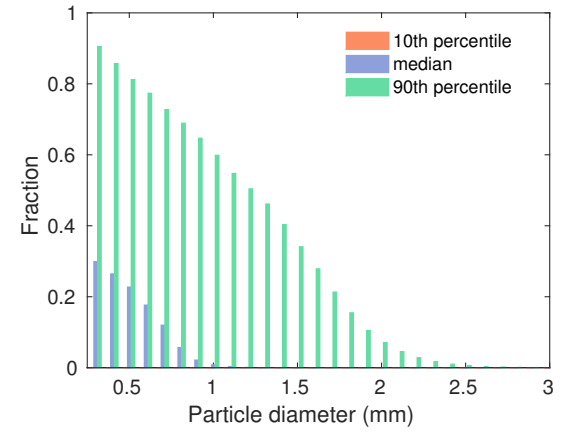

(a) Columns and Plates

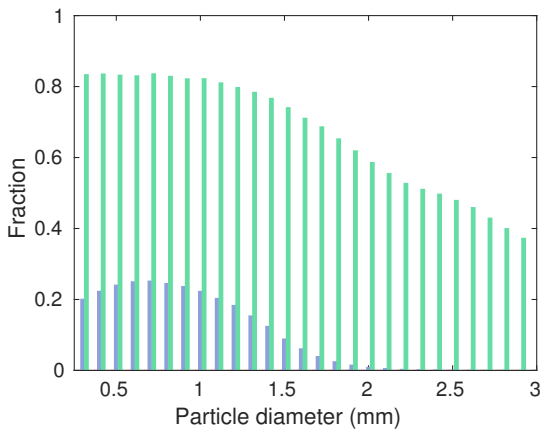

(c) Dendrites and sector

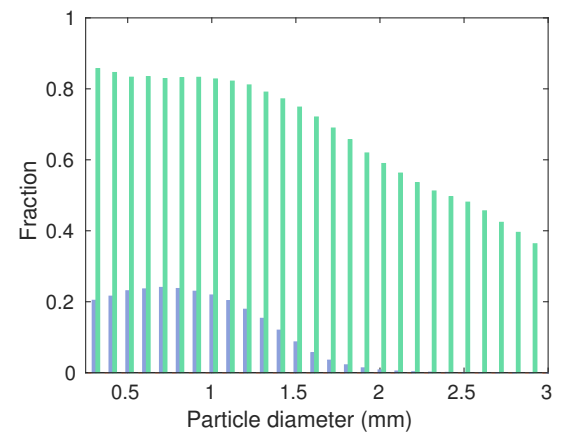

(b) Rosettes

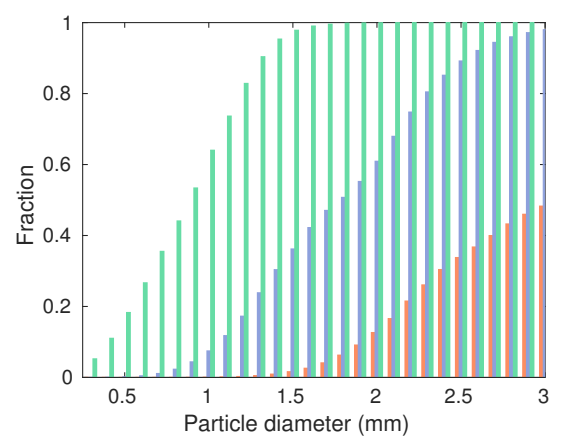

(d) Aggregates

Figure 3: Median, $10^{\text {th }}$ and $90^{\text {th }}$ percentile shape occurrence probability distributions for different particle shapes based on the parameters of the gamma distribution defined in Tab. 1 


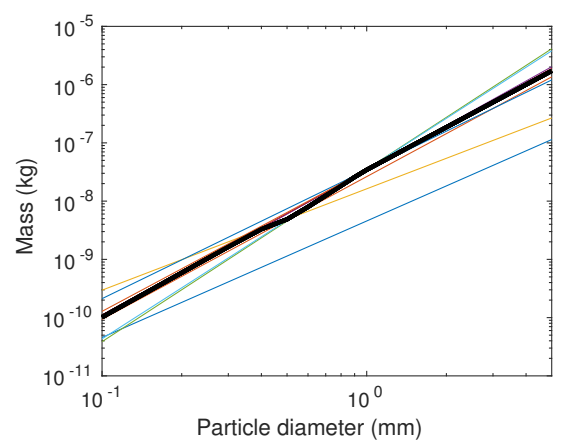

(a) Columns and Plates

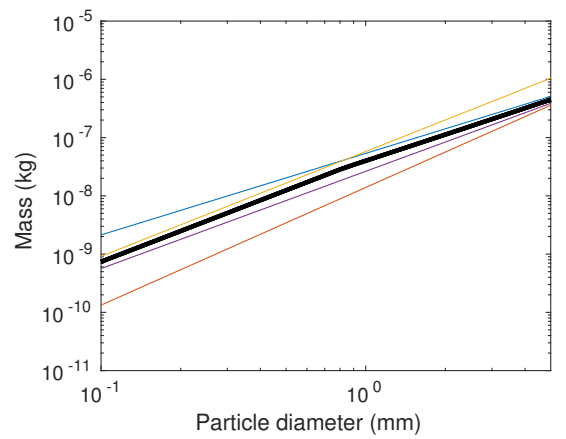

(c) Dendrites and sector

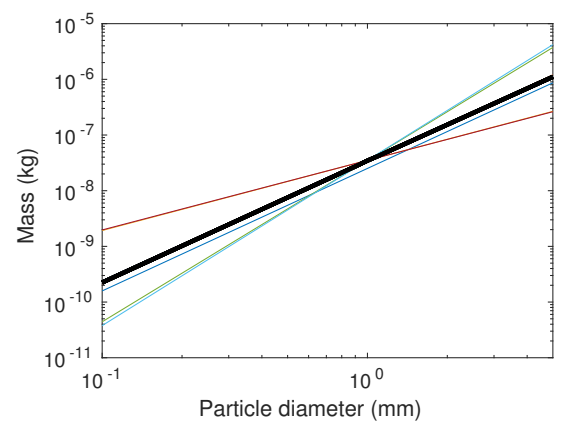

(b) Rosettes

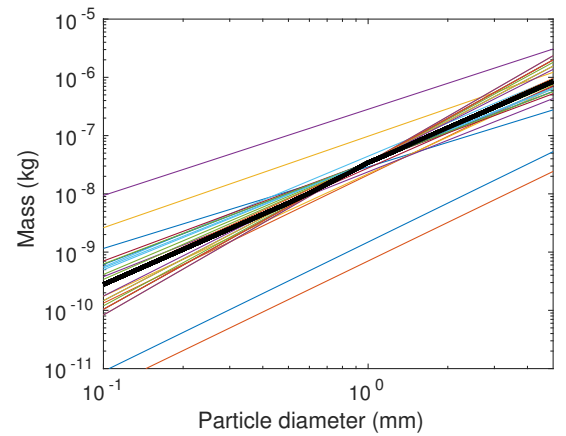

(d) Aggregates

Figure 4: Mass parametrisations from Tab. S2 (Supplementary Information) for different particle shapes. Different colors denote different parametrisations. The median relation is indicated by the thick black line.

S2 (Supplementary Information) and Fig. 44. Relations for rimed crystals are excluded from the list, which is a valid assumption over Antarctica as all precipitation is considered to be 'dry' snowfall (Matrosov, 2007).

\subsubsection{Backscatter cross section}

The backscatter cross section of a snow particle, when measured by millimeter radars, is found to be sensitive to its shape, diameter, mass and orientation (Hong, 2007). Most particles have diameters that are much smaller than the MRR wavelength. Therefore, we are predominately confined to the Rayleigh scattering regime, although some of the larger snow particles might 
slightly deviate from pure Rayleigh scattering (Field et al., 2005, Kneifel et al. 2011). Several methods are available to calculate the backscatter cross section of snow particles including T-matrix (Mishchenko et al., 1996) or the discrete dipole approximation (Draine and Flatau, 1994). In our study the self-similar Rayleigh-Gans approximation (SSRGA) is used, which is a fairly simple method as it only uses a 1D description of the structure of a snow particle Hogan and Westbrook, 2014 Hogan et al., 2017). The SSRGA derives the scattering properties for an ensemble of particles, which is much closer to real radar volumes compared to single type measurements. The SSRGA was evaluated by Hogan et al. (2017), stating it provides a good estimate of the backscatter cross section compared to the more computationally expensive discrete dipole approximation in the Rayleigh regime.

The SSRGA only requires basic input parameters such as the mass of the particle and some parameters describing the particle shape. This also implies that uncertainties from the mass (Tab. S2 (Supplementary Information) and section 2.3.5 propagate into the backscatter cross section and form the main source of uncertainty (Fig. 2). Note that the SSRGA was originally developed for aggregates. It is clear that most of the particles observed at the Princess Elisabeth station and Antarctica have a different structure. To check the validity of the SSRGA method, a comparison with the single particle scattering database of Liu (2008) simulated in lab conditions is performed. A reasonable agreement within uncertainty bounds of the SSRGA and the single-scattering database is found for dendrites and rosettes, but an underestimation of column and plate backscatter is observed (Fig. S1 (Supplementary Information)). In snow storms with a lot of columns and plates this might lead to an underestimation of Ze.

\subsubsection{Terminal fall velocity}

In literature, a large variability in terminal fall velocity parametrisations for different snow particle shapes is found (Locatelli and Hobbs, 1974, Heyms-

400 field and Westbrook, 2010). In this study, the approximation of Heymsfield and Westbrook (2010) is chosen, which is a modification of the formulation of 
Mitchell (1996). In this definition, the terminal fall velocity of a snow particle is calculated by explicitly accounting for drag forces. In practice, this implies that both the mass and the area ratio of the particles are required as an input. The area ratio is defined as the ratio of a particle's projected cross-sectional area to the area of a circle having the particle's maximum diameter (Heymsfield and Miloshevich, 2003). The area-ratio relation with diameter is often approximated by a power law relation of the form $\mathrm{A}_{r}=\mathrm{aD}^{\mathrm{b}}$ and usually decreases towards larger diameters $(b<0)$. As the PIP only measures a 2 D-projection of the snow particle, it is impossible to calculate the area-ratio in a correct way. Therefore, a literature overview of area-ratio parametrisations for different shapes is obtained (Tab. S3 (Supplementary Information)). The mass of the snow particles is obtained from the list defined in section 2.3.5 (Tab. S2 (Supplementary Information) and Fig. 4. These relations are used as input and their uncertainties propagate in the fall speed calculation (Fig. 2). By sampling random relations from Tab. S2 and Tab. S3 (Supplementary Information), the median fall velocity together with the $10^{\text {th }}-90^{\text {th }}$ percentiles are calculated (Fig. 5).

As stated in section 2.1. the PIP is able to calculate the fall velocity of individual snow particles when they are identified in at least two successive frames. Terminal fall velocity measurements are preferably obtained during low horizontal wind speed conditions. From all measurements, periods with horizontal wind speeds lower than $1 \mathrm{~m} / \mathrm{s}$ were sampled, allowing to calculate a median terminal fall velocity together with the $10^{\text {th }}-90^{\text {th }}$ percentile (total number of particles $=100,498)$. Agreement between the observations and the calculated tainty is slightly underestimated for the lowest size bins (Fig. 5). For smallest particles, the agreement is less pronounced and the method of Heymsfield and Westbrook (2010) underestimates the terminal fall speed of the particles. This underestimation is however commonly observed for smallest particle sizes (e.g. 430 Zawadzki et al. 2010, their Fig. 10). 


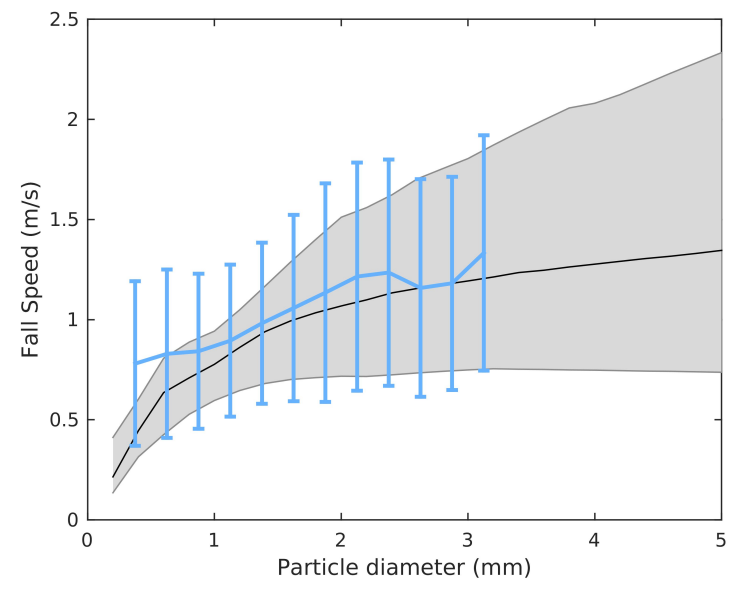

Figure 5: Median and $10^{\text {th }}-90^{\text {th }}$ percentile terminal fall velocity calculated following the approach of Heymsfield and Westbrook 2010) (grey). The average of the direct measurements from the PIP $(\mathrm{N}=100,498)$ is shown including error bars showing $10^{\text {th }}$ and $90^{\text {th }}$ percentiles (blue).

\subsubsection{Uncertainty estimation approach}

In order to obtain a realistic idea of the uncertainty of the Ze-SR relation, a bootstrapping approach is used to sample all snow storms 10,000 times. Measurement uncertainty was included by assuming the uncertainties in diameter and PSD are normally distributed, using the central limit hypothesis and the theory of Wood et al. (2013). For each of the 10,000 simulations, an uncertainty was randomly chosen from this normal distribution. Shape uncertainty was included by selecting different particle shape occurrence probability distributions. Parameters for the particle type gamma distribution of every particle are sampled from a uniform distribution within the range stated in Tab. 1 (see also section 2.3.4). Parameter uncertainty is present in the choice of the mass and area ratio parametrisation for every particle shape and propagates into the terminal fall velocity and backscatter cross section estimation. One relation from Tab. S2 and S3 (Supplementary Information) is sampled randomly for every particle shape for each of the 10,000 simulations using bootstrapping. Furthermore, by performing the bootstrapping on each snow storm separately, 
also differences between the characteristics of individual snow storms are taken into account. As a result Ze, SR are calculated for every minute of data for each of the bootstrapping simulations for each individual snow storm. The parameters of the Ze-SR relation are calculated 120,000 times (10,000 bootstrapping simulations $* 12$ snow storms).

First, the uncertainty of Ze (Eq. 1) and SR (Eq. 2) have been quantified. The four different uncertainty terms will be considered individually as well as the total uncertainty. Ze values obtained by PIP will be compared with the MRR in order to determine if radar measurements can be considered a good proxy for conditions at the surface level. Second, the uncertainty of the resulting Ze-SR relation was calculated. Due to non-linear effects in the power relation between the prefactor and exponent of the Ze-SR relation, the uncertainty of the Ze-SR relation is presented in terms of its effect on the resulting $\mathrm{SR}\left(\mathrm{SR}=\left(\frac{\mathrm{Ze}}{\mathrm{A}}\right)^{\frac{1}{B}}\right)$ averaged over a range of Ze values that is commonly observed over the Princess Elisabeth station. Third, a resulting average Ze-SR relation is presented and its applicability for other locations over the AIS is discussed. All uncertainties are presented in terms of the $10^{\text {th }}$ and $90^{\text {th }}$ percentiles.

\section{Results and discussion}

\subsection{Uncertainty estimates}

\subsubsection{Measurement uncertainty}

One of the most important uncertainties in deriving a Ze-SR relation is the PSD. As the PIP measures the PSD directly, this uncertainty term is limited to measurement errors of the instrument. The magnitudes of these errors are relatively small (section 2.3.2 and 2.3.3). However, uncertainties in the diameter of the particle also propagate into other parameters where the particle diameter is used as input e.g. backscatter cross section, mass and terminal fall velocity (see Fig. 2). This adds to an uncertainty of up to $35 \%$ on the Ze calculation (Eq. 1) and close to $20 \%$ on the SR calculation (Eq. 2) (Tab. 2). Uncertainties 


\begin{tabular}{|l|c|c|c|}
\hline Uncertainty & Ze & SR & Ze-SR relation \\
\hline Measurement & {$[-30 \%+41 \%]$} & {$[-21 \%+27 \%]$} & {$[-10 \%+11 \%]$} \\
\hline Shape & {$[-23 \%+42 \%]$} & {$[-13 \%+14 \%]$} & {$[-11 \%+12 \%]$} \\
\hline Parameter & {$[-52 \%+106 \%]$} & {$[-59 \%+56 \%]$} & {$[-39 \%+38 \%]$} \\
\hline Snow storm variability & $/$ & $/$ & {$[-36 \%+66 \%]$} \\
\hline Total & {$[-59 \%+132 \%]$} & {$[-54 \%+77 \%]$} & {$[-59 \%+60 \%]$} \\
\hline
\end{tabular}

Table 2: $10^{\text {th }}$ and $90^{\text {th }}$ percentile uncertainties on the estimates of Ze (Eq. 1) and SR (Eq. 2 and the uncertainty of the derived Ze-SR relations.

are generally higher for Ze compared to SR, which can be explained by the sensitivity of backscatter cross section to diameter uncertainty. Since backscatter cross section can vary several orders of magnitude within the range of hundreds of $\mu \mathrm{m}$, it can result in large variations in Ze and its uncertainties.

Remarkably, the uncertainty of the Ze-SR relation, which lies around 10\%, is of a lower magnitude than the individual uncertainties on Ze and SR, which is also visible in the other uncertainty terms (Tab. 2p). This can be explained by investigating the uncertainty propagation. For example, as uncertainties in particle size are found in both Ze and SR, an overestimation of particle sizes leads to an increase in both Ze and SR. As the uncertainty of the Ze-SR relation is mainly determined by variations in the prefactor and exponent, a perturbation in a similar direction for both Ze and SR leads mostly to shifts along the Ze-SR relation, only having limited influence on the resulting prefactor and exponent of the Ze-SR relation. This leads to a lower uncertainty of Ze-SR relations than was considered in the past.

\subsubsection{Shape uncertainty}

Shape uncertainty denotes the uncertainty of the shape of the particles. This term has a similar magnitude compared to the measurement uncertainty (Tab. 22. Many authors have stressed the importance of determining the correct particle shape when deriving a Ze-SR relation (e.g. Huang et al., 2015). However, its impact on the uncertainty of Ze, SR and the resulting Ze-SR relation is limited 
compared to the parameter uncertainty (Tab. 2). Different particle shapes have varying masses, terminal fall velocities and backscatter cross sections. Backscatter cross section has mass as an input, while terminal fall velocity is determined by the mass and the area ratio of the snow particles. Uncertainties are therefore mainly determined by the mass and area ratio of snow particles (Fig. 2). As for previous uncertainty terms, in order to isolate shape uncertainty, the other uncertainties are set to zero. The median mass-size (and area ratio-size) relation is selected for each particle shape (thick black lines in Fig. 4) and the differences between these median relations can therefore be considered the main drivers of shape uncertainty.

\subsubsection{Parameter uncertainty}

Parameter uncertainty is the largest uncertainty term, contributing most to the total uncertainty in Ze, SR and the resulting Ze-SR relation, when neglecting PSD variability between snow events (Tab. 2). Parameter uncertainty is mainly determined by the mass and in a more limited way by the area ratio of snow particles (Fig. 2). In each of the 10,000 bootstrapping simulations, for each particle shape separately one parametrisation from Tab. S2 and S3 (Supplementary Information) is chosen within its specific shape. It is noted that the variability within each particle shape is larger than the variability between the median relations of different particle classes. While the uncertainty in the mass of most particle shapes spans a large part of the total spectrum (parameter uncertainty), the median relations of particle shapes resemble each other (shape uncertainty). This is the main reason for the dominance of parameter uncertainty and the low magnitude of shape uncertainty. This stresses the importance of reducing the uncertainty of particle mass estimates for each particle class as a first step in order to lower the uncertainty of the Ze-SR relation.

As was also noted for the measurement uncertainty, the effect of the parameter uncertainty of the Ze-SR relation is still limited compared to the uncertainty of Ze and SR. This can be attributed to similar compensating errors as stated in section 3.1.1 mass and area ratio parametrisations are used in the calculation 
of both Ze and SR and both are perturbed in a similar way. This leads mostly to variability along the Ze-SR relation, not influencing the prefactor and exponent too much.

\subsubsection{Snow storm variability}

Snow storm characteristics vary from event to event, having a profound impact on the values of Ze, SR and the resulting Ze-SR relation as the PSD is used as input for both the calculation of Ze as SR (Eq. 11 \& 2). Note that the snow storms observed by PIP are representative for the precipitation over the station, as the full observed spectrum of reflectivity values is covered might differ when expanding the sampling period.

\subsection{Radar-derived reflectivity measurements}

PIP data products are obtained at the surface level. In this section, the validity of direct MRR Z measurements at $300 \mathrm{~m}$ a.g.l. as a proxy for conditions and $90^{\text {th }}$ percentile of the bootstrapping simulations taking into account all uncertainties discussed above (Fig. 6). Comparing results to the median, a good match between the MRR and the PIP is found for the highest $\mathrm{Z}$ values. A small overestimation in PIP Z can be identified (Fig. 6a), but the 1:1 relation falls 550 within the uncertainty range marked by the $10^{\text {th }}$ and $90^{\text {th }}$ percentile (Fig. $6 \mathrm{~b}$ and 6c). For lower $\mathrm{Z}$ values however, the mismatch between the MRR and the PIP becomes increasingly larger and a clear underestimation by PIP Z values is observed. In section 2.1, the discrepancy in the height of the data acquisition of the MRR and the PIP was discussed including the application of the correction 
of Wood (2011). This simple correction contributes to a better agreement between both quantities for the highest $\mathrm{Z}$ values, but only marginally impacts the lowest ones. During these minor snowfall events, the correction of Wood (2011) is not sufficient and other processes seem to play a role in decreasing the amount of snowfall between the lowest measurement bin of the MRR (300m a.g.l.) and the surface. Increased low-level sublimation is a process that might explain (part of) this discrepancy and is mainly controlled by temperature, wind speed and relative humidity (Lenaerts et al. 2010, Thiery et al., 2012). A clear negative correlation between relative humidity at the surface and the discrepancy in $\mathrm{Z}$ between the MRR and the PIP was identified over the Princess Elisabeth station (Fig. S2 (Supplementary Information)). This suggests an active and more pronounced role for sublimation in the lowest layers of the atmosphere, limiting the amount of precipitation reaching the ground during these small precipitation events. The inconsistency between both instruments is, however, not considerably affecting our results as highest $\mathrm{Z}$ values are most important in our study, since these also correspond to highest SR and snow accumulation.

\subsection{Reflectivity - snowfall rate relation for Princess Elisabeth and its applica-} bility over Antarctica

The total uncertainty of the Ze-SR relation is mainly determined by parameter uncertainty (Tab. 2). This term contributes to almost all uncertainty of the Ze-SR relation and is mainly determined by the uncertainty of the mass for every specific particle. From the bootstrapping simulations, a median Ze and $\mathrm{SR}$ value is obtained that is used to calculate the prefactor and exponent of the Ze-SR relation valid for the Princess Elisabeth station (Fig. 7). Every dot denotes one minute of data, while the resulting Ze-SR relation is denoted by the thick black line. The dashed lines in the background show relations found by other authors. The black lines show the observations of Matrosov (2007), while grey lines denote the relations of Kulie and Bennartz (2009), both derived for $\mathrm{K}_{\mathrm{a}}$-band radar frequencies. The comparability of these relations with our radar (operating on K-band) is satisfactory for the PSDs and snowfall rates observed 


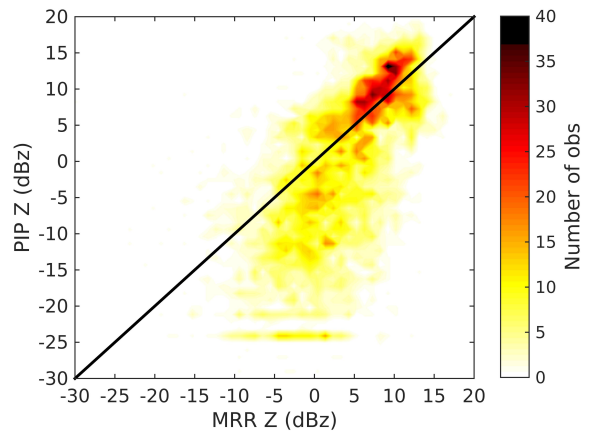

(a) Ensemble Mean

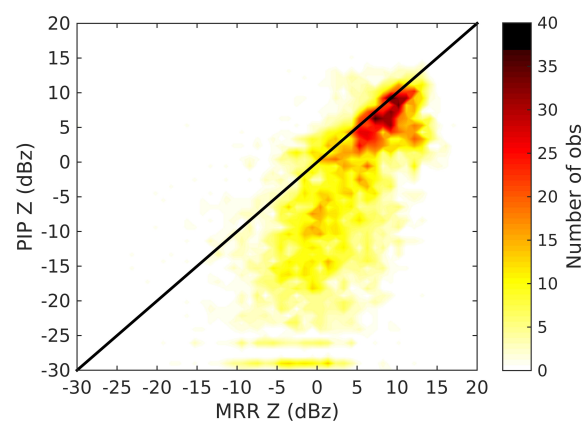

(b) $10^{\text {th }}$ percentile

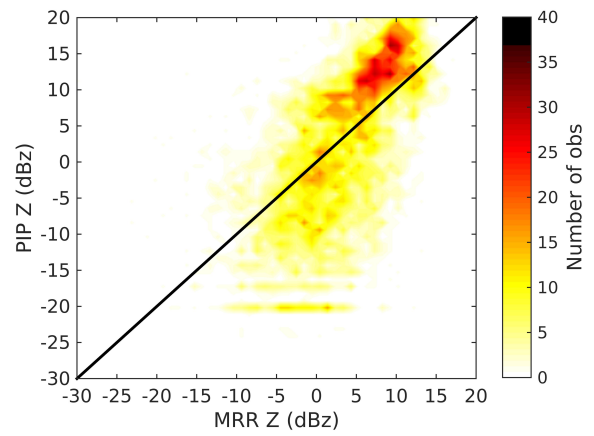

(c) $90^{\text {th }}$ percentile

Figure 6: Comparison of the $\mathrm{Z}$ values measured by the MRR and the ensemble mean, $10^{\text {th }}$ and $90^{\text {th }}$ percentile of the bootstrapping simulations of the PIP. 


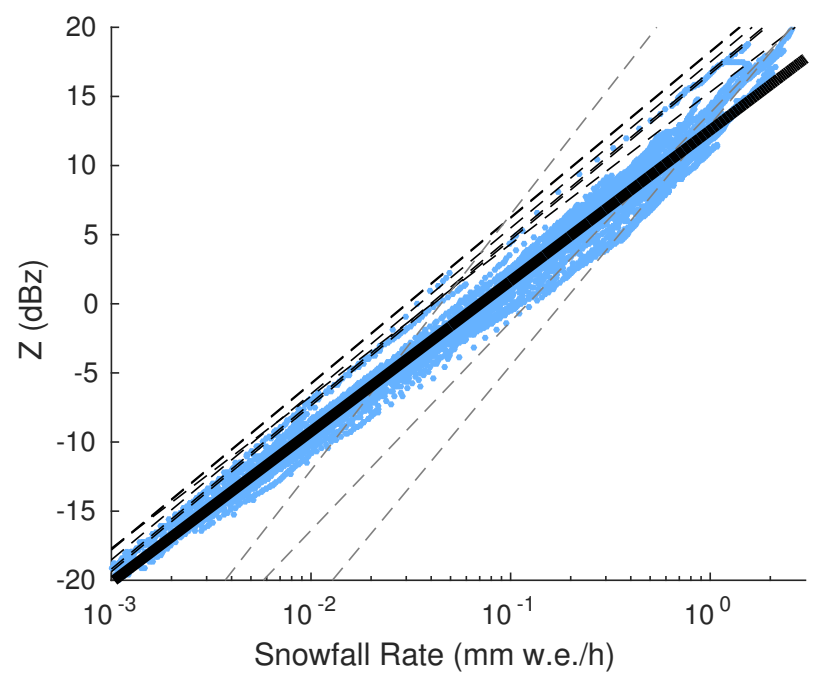

Figure 7: Ensemble Z and SR values of 12 distinct snow storm over Princess Elisabeth derived from the median of the bootstrapping simulations (blue dots). Dashed black and grey lines denote relations obtained from literature (Matrosov (2007) and Kulie and Bennartz (2009) respectively), while the thick black line indicates the resulting average Ze-SR relation for the Princess Elisabeth station.

at the Princess Elisabeth station (Fig. S3 and S4 (Supplementary Information)). The following relation is obtained: $\mathrm{Ze}=18 \mathrm{SR}^{1.1}$. The exponent matches closely with the exponent of the simulations of Matrosov (2007), but is generally lower than the results of Kulie and Bennartz (2009) and Matrosov et al. (2009). The variability in the value for the exponent is low between different snow storms. Limited variability in the exponent for a specific location has also been observed at other locations (von Lerber et al., 2017), while other research denotes higher variability in the value of the exponent (Huang et al., 2010, 2015).

The total uncertainty of the Ze-SR relation is limited to approximately $40 \%$ (Tab. 2). This is mostly reflected in variations in the prefactor value ([11-43]), while the exponent stays approximately constant ([0.97-1.17]) (Fig. 8). This uncertainty range is calculated based on the calculation of the Ze-SR relation for every storm separately for every bootstrapping simulation. As such, the uncertainty range can be compared to natural variability, which is captured 


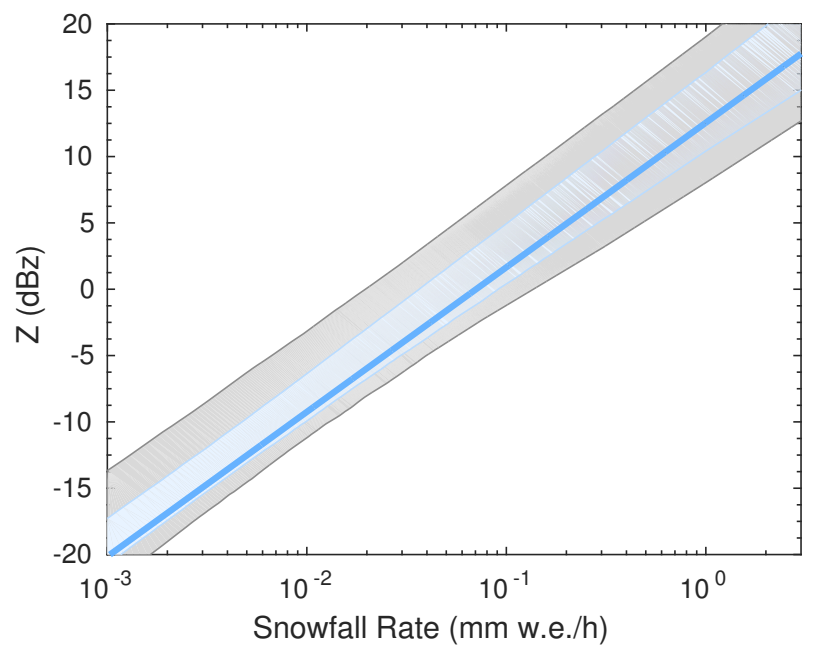

Figure 8: The $10^{\text {th }}$ and $90^{\text {th }}$ percentile uncertainty (blue shaded area) and the $1^{\text {st }}$ and $99^{\text {th }}$ percentile (grey shaded area) on the Ze-SR relation of all 12 snow storms with each 10,000 bootstrapping simulations. The ensemble average relation is denoted by the thick blue line.

adequately (compare Fig. 7 and 8 .

We state that the uncertainty of the Ze-SR relation is smaller over the Princess Elisabeth station compared to other Antarctic stations and connect this to the specific size of the particles that are observed at this location. The median size of the particles ranges around $0.7 \mathrm{~mm}$. In case the spectrum was dominated by particles that are larger or smaller, the uncertainties on $\mathrm{Ze}$ and SR would be higher, as well as the uncertainties on the Ze-SR relation. This can be attributed to the mass parametrisations, being the most important source of uncertainty to the Ze, SR and Ze-SR. The variability between mass-diameter relations is smaller for the diameters close to $1 \mathrm{~mm}$, while for larger and smaller particles, the range of uncertainty becomes bigger (clearly visible for rosettes 610 and aggregates; Fig. 44. This implies that smallest uncertainties would be found for particle probability shape occurrence distributions having a median diameter close to $1 \mathrm{~mm}$.

A sensitivity study was executed to test this hypothesis. First, particle sizes were doubled, based on PSDs observed over the station leaving the counts 

et al. (2011) for liquid precipitation but has also been observed for snowfall by Tiira et al. (2016) over Finland and Konishi et al. (1992) for a limited sample at Syowa station, Antarctica. This also explains the higher values of the prefactor for the experiment of Matrosov (2007) as their samples consisted of larger snow

unchanged (but adapting the particle shapes adequately). This shows that the Ze uncertainty increases to $[-66 \%+197 \%]$, while for SR a range of $[-57 \%+96 \%]$ is found. Secondly, the particle sizes were halved using the same approach as above, leading to Ze uncertainties of $[-60 \%+157 \%]$ and SR uncertainties ranging between $[-55 \%+114 \%]$, profoundly higher values than for the original sample (Tab. 2). This also implies that near the coast of Antarctica, where SR is higher and larger particle sizes are observed, the uncertainties on resulting Ze-SR relation becomes bigger. The same is true for more inland sites, where particle sizes usually do not exceed $1 \mathrm{~mm}$. It must be noted that riming is not considered in our calculations as all snowfall over Princess Elisabeth is considered dry snow. At coastal regions however, riming processes do take place, further increasing the uncertainty of particle masses and having a profound effect on the uncertainty of the prefactor of the Ze-SR relation von Lerber et al., 2017). Furthermore, it must be noted that the PSD might be different at other locations over Antarctica. The simple sensitivity study perturbing the size of the snow particles therefore only gives a first order approximation of how the uncertainty on Ze and SR changes. PSD measurements obtained from other sites over Antarctica would contribute largely to this problem.

Particle sizes do not only impact the magnitude of the uncertainty of the Ze-SR relation, but also the mean value of the prefactor and exponent. The sensitivity studies executed above denote largest impacts on the prefactor, while no significant change in the exponent B is observed. If the PSD consists of larger elements (as is the case at the coast of Antarctica), the prefactor gets larger (44 [35-60]), while for smaller particles, a lower value for the prefactor is found ( 8 [7-17]). Similar sensitivities caused by changes in the PSD were observed by Sempere Torres et al. (1994); Atlas et al. (1999); Uijlenhoet (2001); Hazenberg particles. It is again noted that the PSD might be different at other locations 
over Antarctica compared to Princess Elisabeth. Aggregation and riming might have an important influence on the PSD.

\section{Conclusions}

Previous studies successfully developed radar reflectivity-snowfall rate relations (Ze-SR relations) for different parts of the world using disdrometers and ground-based radars. However, over Antarctica, such a study has not yet been performed. Using the Precipitation Imager Package (PIP) and a Micro Rain Radar (MRR), a Ze-SR relation $\left(\mathrm{Ze}=\mathrm{A}^{*} \mathrm{SR}^{\mathrm{B}}\right.$ ) over Antarctica was derived by performing bootstrapping simulations taking different uncertainty terms into account. The prefactor (A) was estimated to be 18 (with an uncertainty range [11-43]), while B equals 1.10 (with an uncertainty of [0.97-1.17]). This relation and its uncertainty can be applied to the MRR reflectivity measurements in order to obtain long-term records of snowfall rates using relatively compact low-power equipment, including an improvement of current uncertainty ranges.

First, an estimate of the measurement, shape and parameter uncertainty for radar reflectivity (Ze), snowfall rate (SR) and the Ze-SR relation were obtained. This study demonstrates that, in case the particle size distribution (PSD) is measured directly, the uncertainty of the Ze-SR relation is dominated by parameter uncertainty and more specifically by the uncertainty of the mass of the different snow particles. In contrast with previous research, this uncertainty term is larger than the uncertainty of the shape of the particle. The uncertainty of mass parametrisations for each particle shape is higher than the variability in median mass estimates between different shapes (Fig. 4). In order to lower the uncertainty of the Ze-SR relation, it is therefore crucial to reduce the uncertainty of particle mass estimates for the individual particle shapes first. This should be a key point to be addressed in future research. Only then, particle shape detection might help lower the uncertainty of the Ze-SR relation even further.

Another important contributor to the uncertainty in the Ze-SR relation is 

attributes to even larger variability in the prefactor and exponent of the Ze$\mathrm{SR}$ relation than the three uncertainty terms discussed previously. However, it cannot be considered a systematic error as the other three terms as it depends on the sampling period. leads to large uncertainties of Ze and SR estimates ([-59\%+132\%] and [-54\% $+77 \%$ ] respectively). However, this does not immediately result in large uncertainties on derived snowfall rates by the MRR based on the resulting Ze-SR relations $([-59 \%+60 \%])$. This can be explained by focusing on the uncertainty particles (found at other locations on the continent) lead to higher uncertainties on Ze and SR, as the spread of mass estimates derived from literature is smallest for particle diameters around $1 \mathrm{~mm}$. This again stresses the importance of reducing the uncertainty of mass parametrisations of snow particles. fluences the average value of the prefactor of the Ze-SR relation. Increases (decreases) in the particle diameter lead to an increase (a decrease) in the value of this prefactor, while changes in the value of the exponent are limited. As particles are usually small over Antarctica, this explains the lower values of 
particle diameters on the prefactor of the Ze-SR relation can lead to substantial differences in the resulting snowfall rates. It must be noted that the PSD might be different at other locations over Antarctica due to e.g. riming and aggregation. This is not taken into account in this sensitivity study.

The low uncertainties on the Ze-SR relation for small snow particles opens perspectives for research with disdrometers and the application of compact lowpower radars over Antarctica in order to derive accurate estimates of snowfall rates. As such, an expansion of disdrometer and radar employment to other sites is opportune. Furthermore, the importance of reliable mass estimates of snow particles is of paramount importance in order to lower uncertainties. A first attempt to obtain density measurements for the PIP was recently obtained, showing promising results (Tiira et al., 2016). Another approach uses triplefrequency radars, recently showed a high correlation between snowfall densities and its scattering signatures (Kneifel et al. 2015). These studies are considered a good first step, but an expansion to other locations and instruments is necessary.

\section{Acknowledgements}

We thank the logistic teams, Alexander Mangold (Royal Meteorological Institute) and Quentin Laffineur (Royal Meteorological Institute) for executing the yearly maintenance of our instruments at the Princess Elisabeth station and for their help by installing and setting up the PIP. Christophe Coeck (KU Leuven) is acknowledged for designing and constructing a frame for the PIP adapted to the Antarctic climate. Alain Protat (Bureau of Meteorology, Melbourne) is thanked for performing the calibration of our MRR, highly improving confidence in its measurements. We further thank Wim Boot, Carleen Reijmer, and Michiel van den Broeke (Utrecht University, Institute for Marine and Atmospheric Research Utrecht) for the development of the Automatic Weather Station, technical support and raw data processing. The authors are grateful to two anonymous reviewers for their constructive reviews. This work was supported by the Belgian Science Policy Office (BELSPO; grant number BR/143/A2/AEROCLOUD) and 
Agosta, C., Fettweis, X., Datta, R., 2015. Evaluation of the CMIP5 models in the aim of regional modelling of the Antarctic surface mass balance. The Cryosphere 9, 2311-2321. doi:10.5194/tc-9-2311-2015.

Atlas, D., Matrosov, S.Y., Heymsfield, a.J., Chou, M.D., Wolff, D.B., 1995. $\mathrm{CO} ; 2$.

Atlas, D., Ulbrich, C.W., Marks, F.D., Amitai, E., Williams, C.R., 1999. Systematic variation of drop size and radar-rainfall relations. Journal of Geophys-

Battan, L.J., 1973. Radar Observation of the Atmosphere. The University of Chicago Press.

Berne, A., Krajewski, W.F., 2013. Radar for hydrology: Unfulfilled promise or n unrecognized potential? Advances in Water Resources 51, 357-366. doi 10. 1016/j.advwatres.2012.05.005

Brandes, E.A., Ikeda, K., Thompson, G., Schönhuber, M., 2008. Aggregate terminal velocity/temperature relations. Journal of Applied Meteorology and Climatology 47, 2729-2736. doi 10.1175/2008JAMC1869.1

Brandes, E.A., Ikeda, K., Zhang, G., Schönhuber, M., Rasmussen, R.M., 2007.

A statistical and physical description of hydrometeor distributions in Colorado 
snowstorms using a video disdrometer. Journal of Applied Meteorology and Climatology 46, 634-650. doi 10.1175/JAM2489.1.

Bromwich, D.H., Guo, Z., Bai, L.S., Chen, Q.S., 2004. Modeled Antarctic Precipitation. Part I: spatial and temporal variability. Journal of Climate 17, 427-447. doi:10.1175/1520-0442(2004)017<0427 :MAPPIS>2.0.C0;2

Brown, P.R.A., Francis, P.N., 1995. Improved Measurements of the Ice

n Water Content in Cirrus Using a Total-Water Probe. doi 10.1175/ 1520-0426(1995)012<0410: IMOTIW>2.0.CO;2

Draine, B.T., Flatau, P.J., 1994. Discrete-dipole approximation for scattering calculations. Journal of the Optical Society of America A 11, 1491-1499. doi:10.1364/JOSAA.11.001491.

Field, P.R., Hogan, R.J., Brown, P.R.A., Illingworth, A.J., Choularton, T.W., Cotton, R.J., 2005. Parametrization of ice-particle size distributions for midlatitude stratiform cloud. Quarterly Journal of the Royal Meteorological Society $131,1997-2017$. doi:10.1256/qj.04.134.

Genthon, C., Magand, O., Krinner, G., Fily, M., 2009. Do climate models underestimate snow accumulation on the Antarctic plateau? A re-evaluation of/from in situ observations in East Wilkes and Victoria Lands. Annals of Glaciology 50, 61-65. doi $10.3189 / 172756409787769735$

Gorodetskaya, I.V., Kneifel, S., Maahn, M., Van Tricht, K., Thiery, W., Schween, J.H., Mangold, A., Crewell, S., Van Lipzig, N.P.M., 2015. Cloud and precipitation properties from ground-based remote sensing in口 struments in East Antarctica. The Cryosphere 9, 285-304. doi 10.5194/ tcd-8-4195-2014

785 Gorodetskaya, I.V., Tsukernik, M., Claes, K., Ralph, M., Neff, W., Van Lipzig, N.P.M., 2014. The role of atmospheric rivers in anomalous snow accumulation 口 in East Antarctica. Geophysical Research Letters 16, 6199-6206. doi 10. 1002/2014GL060881. 
Gorodetskaya, I.V., Van Lipzig, N.P.M., Van Den Broeke, M.R., Mangold, a.,

Boot, W., Reijmer, C.H., 2013. Meteorological regimes and accumulation patterns at Utsteinen, Dronning Maud Land, East Antarctica: Analysis of two contrasting years. Journal of Geophysical Research: Atmospheres 118, 1700-1715. doi $10.1002 /$ jgrd.50177

Hazenberg, P., Yu, N., Boudevillain, B., Delrieu, G., Uijlenhoet, R., 2011. Scaling of raindrop size distributions and classification of radar reflectivity-rain rate relations in intense Mediterranean precipitation. Journal of Hydrology 402, 179-192. doi:10.1016/j.jhydrol.2011.01.015

Heymsfield, A.J., Miloshevich, L.M., 2003. Parameterizations for the CrossSectional Area and Extinction of Cirrus and Stratiform Ice Cloud Par800 ticles. Journal of the Atmospheric Sciences 60, 936-956. doi 10.1175/ 1520-0469(2003)060<0936:PFTCSA>2.0.C0;2.

Heymsfield, A.J., Westbrook, C.D., 2010. Advances in the Estimation of Ice Particle Fall Speeds Using Laboratory and Field Measurements. Journal of the Atmospheric Sciences 67, 2469-2482. doi 10.1175/2010JAS3379.1.

Hogan, R.J., Honeyager, R., Tyynelä, J., Kneifel, S., 2017. Calculating the millimetre-wave scattering phase function of snowflakes using the Self-Similar Rayleigh-Gans Approximation. Quarterly Journal of the Royal Meteorological Society doi:10.1002/qj.2968

Hogan, R.J., Tian, L., Brown, P.R.A., Westbrook, C.D., Heymsfield, A.J., Eastment, J.D., 2012. Radar scattering from ice aggregates using the horizontally aligned oblate spheroid approximation. Journal of Applied Meteorology and Climatology 51, 655-671. doi 10.1175/JAMC-D-11-074.1.

Hogan, R.J., Westbrook, C.D., 2014. Equation for the microwave backscatter cross section of aggregate snowflakes using the Self-Similar Rayleigh-Gans 815 . Approximation. Journal of the Atmospheric Sciences 71, 3292-3301. doi 10. 1175/JAS-D-13-0347.1. 
Hong, G., 2007. Radar backscattering properties of nonspherical ice crystals at

94 GHz. Journal of Geophysical Research Atmospheres 112, D22203. doi 10. 1029/2007JD008839.

Huang, G.J., Bringi, V., Moisseev, D., Petersen, W., Bliven, L., Hudak, D., 2015. Use of 2D-video disdrometer to derive mean density-size and Ze-SR relations: Four snow cases from the light precipitation validation experiment. Atmospheric Research 153, 34-48. doi:10.1016/j .atmosres.2014.07.013.

Huang, G.J., Bringi, V.N., Cifelli, R., Hudak, D., Petersen, W.A., 2010. A methodology to derive radar reflectivity-liquid equivalent snow rate relations using C-band radar and a 2D video disdrometer. Journal of Atmospheric and Oceanic Technology 27, 637-651. doi:10.1175/2009JTECHA1284.1.

Kajikawa, M., 1972. Measurement of Falling Velocity of Individual Snow Crystals. Journal of the Meteorological Society of Japan. Ser. II 50, 577-584. doi:http://doi.org/10.2151/jmsj1965.50.6_577.

Klugmann, D., Heinsohn, K., Kirtzel, H.J., 1996. A low cost 24 GHz FMCW Doppler radar rain profiler. Contributions to Atmospheric Physics 69, $247-253$.

Kneifel, S., von Lerber, A., Tiira, J., Moisseev, D., Kollias, P., Leinonen, J., 2015. Observed relations between snowfall microphysics and triple-frequency radar measurements. Journal of Geophysical Research: Atmospheres 120, 6034-6055. doi $10.1002 / 2015$ JD023156.

Kneifel, S., Maahn, M., Peters, G., Simmer, C., 2011. Observation of snowfall with a low-power FM-CW K-band radar (Micro Rain Radar). Meteorology and Atmospheric Physics 113, 75-87. doi 10.1007/s00703-011-0142-z.

Knuth, S.L., Tripoli, G.J., Thom, J.E., Weidner, G.A., 2010. The influence of blowing snow and precipitation on snow depth change across the Ross Ice Shelf and Ross Sea regions of Antarctica. Journal of Applied Meteorology and Climatology 49, 1306-1321. doi 10.1175/2010JAMC2245.1. 
${ }_{845}$ Konishi, H., Muramoto, K., Shiina, T., Endoh, T., Kitano, K., 1992. Z-R relation for graupels and aggregates observed at Syowa station, Antarctica. Proceedings of the NIPR Symposium on Polar Meteorology and Glaciology 5, $97-103$.

Korolev, A., Isaac, G., 2003. Roundness and Aspect Ratio of Particles in Ice 850 . Clouds. Journal of the Atmospheric Sciences 60, 1795-1808. doi 10.1175/ 1520-0469(2003)060<1795:RAAROP > 2.0.CO;2.

Kulie, M.S., Bennartz, R., 2009. Utilizing spaceborne radars to retrieve dry Snowfall. Journal of Applied Meteorology and Climatology 48, 2564-2580. doi:10.1175/2009JAMC2193.1.

${ }_{855}$ Lachlan-Cope, T., 2010. Antarctic clouds. Polar Research 29, 150-158. doi 10. $1111 / \mathrm{j} .1751-8369.2010 .00148 . \mathrm{x}$

Lachlan-Cope, T., Ladkin, R., Turner, J., Davison, P., 2001. Observations of cloud and precipitation particles on the Avery Plateau, Antarctic Penin-

\ sula. Antarctic Science 13, 339-348. doi:http://dx.doi.org/10.1017/ S0954102001000475.

Lawson, R.P., Baker, B.A., Zmarzly, P., O’Connor, D., Mo, Q., Gayet, J.F., Shcherbakov, V., 2006. Microphysical and Optical Properties of Atmospheric Ice Crystals at South Pole Station. Journal of Applied Meteorology and Climatology 45, 1505-1524. doi:10.1175/JAM2421.1. J., Munneke, P.K., 2010. Modelling snowdrift sublimation on an Antarctic ice shelf. Cryosphere 4, 179-190. doi 10.5194/tc-4-179-2010.

von Lerber, A., Moisseev, D., Bliven, F., Petersen, W., Harri, A.M., Chandrasekar, V., 2017. Microphysical properties of snow and their link to Ze-S relation during BAECC. Journal of Applied Meteorology and Climatology, in press. 
Liu, G., 2008. A database of microwave single-scattering properties for nonspherical ice particles. Bulletin of the American Meteorological Society 89, 1563-1570. doi $10.1175 / 2008$ BAMS2486.1.

Locatelli, J.D., Hobbs, P.V., 1974. Fall speeds and masses of solid precipita-

口 tion particles. Journal of Geophysical Research 79, 2185-2197. doi 10.1029/ JC079i015p02185

Löffler-Mang, M., Blahak, U., 2001. Estimation of the Equivalent Radar Reflectivity Factor from Measured Snow Size Spectra. Journal of Applied Me-

880 ㅁ teorology 40, 843-849. doi:10.1175/1520-0450(2001) 040<0843:EOTERR>2. $0 . \mathrm{CO} ; 2$.

Maahn, M., Burgard, C., Crewell, S., Gorodetskaya, I.V., Kneifel, S., Lhermitte, S., Van Tricht, K., Van Lipzig, N.P.M., 2014. How does the spaceborne radar blind zone affect derived surface snowfall statistics in polar regions ?

885 \ Journal of Geophysical Research: Atmospheres 119, 13604-13620. doi:10. 1002/2014JD022079.

Maahn, M., Kollias, P., 2012. Improved Micro Rain Radar snow measurements using Doppler spectra post-processing. Atmospheric Measurement Techniques 5, 2661-2673. doi:10.5194/amt-5-2661-2012.

Matrosov, S.Y., 2007. Modeling Backscatter Properties of Snowfall at Millimeter

ם Wavelengths. Journal of the Atmospheric Sciences 64, 1727-1736. doi:10. 1175/JAS3904.1.

Matrosov, S.Y., Campbell, C., Kingsmill, D., Sukovich, E., 2009. Assessing snowfall rates from X-Band radar reflectivity measurements. Jour895 „ nal of Atmospheric and Oceanic Technology 26, 2324-2339. doi 10.1175/ 2009JTECHA1238.1.

Matrosov, S.Y., Heymsfield, A.J., Wang, Z., 2005. Dual-frequency radar ratio of nonspherical atmospheric hydrometeors. Geophysical Research Letters 32, L13816. doi:10.1029/2005GL023210. 
Matrosov, S.Y., Shupe, M.D., Djalalova, I.V., 2008. Snowfall retrievals using millimeter-wavelength cloud radars. Journal of Applied Meteorology and Climatology 47, 769-777. doi $10.1175 / 2007$ JAMC1768.1.

Mishchenko, M.I., Travis, L.D., Mackowski, D.W., 1996. T-matrix computations of light scattering by nonspherical particles: a review. Journal of

905 ㅁ Quantitative Spectroscopy and Radiative Transfer 55, 535-575. doi 10.1016/ 0022-4073(96)00002-7.

Mitchell, D.L., 1996. Use of Mass- and Area-Dimensional Power Laws for Determining Precipitation Particle Terminal Velocities. Journal of the Atmospheric Sciences 53, 1710-1723.

910 Mitchell, D.L., Zhang, R., Pitter, R.L., 1990. Mass-Dimensional Relationships for Ice Particles and the Influence of Riming on Snowfall Rates. Journal of 口. Applied Meteorology 29, 153-163. doi 10.1175/1520-0450(1990)029<0153: MDRFIP>2.0.CO;2.

Moisseev, D.N., Chandrasekar, V., 2007. Examination of the mu-Lambda relation suggested for drop size distribution parameters. Journal of Atmospheric and Oceanic Technology 24, 847-855. doi 10.1175/JTECH2010.1.

Nakaya, U., Terada, T., 1935. Simultaneous Observations of the Mass, Falling Velocity and Form of Individual Snow Crystals. Journal of the Faculty of Science, Hokkaido Imperial University. Series 2, Physics 1, 191-200. URL: http://hdl.handle.net/2115/34452.

Newman, A.J., Kucera, P.A., Bliven, L.F., 2009. Presenting the Snowflake Video Imager (SVI). Journal of Atmospheric and Oceanic Technology 26, 167-179. doi:10.1175/2008JTECHA1148.1.

Palerme, C., Genthon, C., Claud, C., Kay, J.E., Wood, N.B., L'Ecuyer, T., 925 2017. Evaluation of current and projected Antarctic precipitation in CMIP5 models. Climate Dynamics 48, 225-239. doi 10.1007/s00382-016-3071-1. 
Palerme, C., Kay, J.E., Genthon, C., L'Ecuyer, T., Wood, N.B., Claud, C., 2014. How much snow falls on the Antarctic ice sheet? The Cryosphere 8, 1577-1587. doi $10.5194 /$ tc-8-1577-2014.

Protat, A., Bouniol, D., Delanoë, J., May, P.T., Plana-Fattori, A., Hasson, A., O'Connor, E., Görsdore, U., Heymsfield, A.J., 2009. Assessment of Cloudsat reflectivity measurements and ice cloud properties using ground-based and airborne cloud radar observations. Journal of Atmospheric and Oceanic Technology 26, 1717-1741. doi:10.1175/2009JTECHA1246.1

${ }_{935}$ Protat, A., Bouniol, D., O'Connor, E.J., Klein Baltink, H., Verlinde, J., Widener, K., 2011. CloudSat as a global radar calibrator. Journal of Atmo口 spheric and Oceanic Technology 28, 445-452. doi 10.1175/2010JTECHA1443. 1.

Protat, A., Delanoë, J., O'Connor, E.J., L'Ecuyer, T.S., 2010. The evaluation of CloudSat and CALIPSO ice microphysical products using ground-based cloud radar and lidar observations. Journal of Atmospheric and Oceanic Technology 27, 793-810. doi $10.1175 / 2009$ JTECHA1397.1

Rasmussen, R., Dixon, M., Vasiloff, S., Hage, F., Knight, S., Vivekanandan, J., Xu, M., 2003. Snow Nowcasting Using a Real-Time Correlation of Radar Reflectivity with Snow Gauge Accumulation. Journal of Applied Meteorology 42, 20-36. doi $10.1175 / 1520-0450$ (2003) 042<0020: SNUART >2 . 0.CO;2

Sekhon, R.S., Srivastava, R.C., 1970. Snow Size Spectra and Radar Refleca tivity. Journal of the Atmospheric Sciences 27, 299-307. doi 10.1175/ 1520-0469(1970)027<0299: SSSARR>2.0.CO;2

950 Sempere Torres, D., Porra, J.M., Creutin, J.D., 1994. A General Formulation for Raindrop Size Distribution. Journal of Applied Meteorology 33, 1494-1502. doi:10.1175/1520-0450(1994)033<1494: AGFFRS>2.0.C0;2.

Stephens, G.L., Vane, D.G., Boain, R.J., Mace, G.G., Sassen, K., Wang, Z., Illingworth, A.J., O'Connor, E.J., Rossow, W.B., Durden, S.L., Miller, S.D., 
Austin, R.T., Benedetti, A., Mitrescu, C., 2002. The cloudsat mission and the A-Train: A new dimension of space-based observations of clouds and precipitation. Bulletin of the American Meteorological Society 83, 1771-1790. doi:10.1175/BAMS-83-12-1771.

Szyrmer, W., Zawadzki, I., 2010. Snow Studies. Part II: Average Relationship between Mass of Snowflakes and Their Terminal Fall Velocity. Journal of the Atmospheric Sciences 67, 3319-3335. doi:10.1175/2010JAS3390.1.

Thiery, W., Gorodetskaya, I.V., Bintanja, R., Van Lipzig, N.P.M., Van den Broeke, M.R., Reijmer, C.H., Kuipers Munneke, P., 2012. Surface and snowdrift sublimation at Princess Elisabeth station, East Antarctica. The Cryosphere 6, 841-857. doi $10.5194 /$ tc-6-841-2012.

Tiira, J., Moisseev, D.N., von Lerber, A., Ori, D., Tokay, A., Bliven, L.F., Petersen, W., 2016. Ensemble mean density and its connection to other microphysical properties of falling snow as observed in Southern Finland. Atmospheric Measurement Techniques 9, 4825-4841. doi 10.5194/amt-2016-192

Uijlenhoet, R., 2001. Raindrop size distributions and radar reflectivity - rain rate relationships for radar hydrology. Hydrology and Earth System Sciences 5, 615-627. doi 10.5194/hess-5-615-2001.

Vaughan, D., Comiso, J., Allison, I., Carrasco, J., Kaser, G., Kwok, R., Mote, P., Murray, T., Paul, F., Ren, J., Rignot, E., Solomina, O., Steffen, K., Zhang, T., 2013. Observations: Cryosphere, in: Stocker, T., Qin, D., Plattner, G.K., Tignor, M., Allen, S., Boschung, J., Nauels, A., Xia, Y., Bex, V., Midgley, P. (Eds.), Climate Change 2013: The Physical Science Basis. Contribution of Working Group I to the Fifth Assessment Report of the Intergovernmental Panel on Climate Change. Cambridge University 980 Press, Cambridge, United Kingdom and New York, NY, USA, pp. 317-382. doi:10.1017/CB09781107415324.012.

Vaughan, D.G., Bamber, J.L., Giovinetto, M., Russell, J., Cooper, A.P.R., 1999. 
Reassessment of net surface mass balance in Antarctica. Journal of Climate 12, 933-946. doi $10.1175 / 1520-0442$ (1999) 012<0933:RONSMB>2.0.C0;2.

Villarini, G., Krajewski, W.F., 2010. Review of the different sources of uncertainty in single polarization radar-based estimates of rainfall. Surveys in Geophysics 31, 107-129. doi:10.1007/s10712-009-9079-x.

Walden, V.P., Warren, S.G., Tuttle, E., 2003. Atmospheric ice crystals over the Antarctic Plateau in winter. Journal of Applied Meteorology 42, 1391-1405. doi:10.1175/1520-0450(2003)042<1391:AICOTA>2.0.C0;2.

Wood, N.B., 2011. Estimation of snow microphysical properties with application to millimeter-wavelength radar retrievals for snowfall rate. $\mathrm{Ph} . \mathrm{D}$. thesis.

a Colorado State University. Colorado. URL: http://hdl.handle.net/10217/ 48170 .

Wood, N.B., L'Ecuyer, T.S., Bliven, F.L., Stephens, G.L., 2013. Characterization of video disdrometer uncertainties and impacts on estimates of snowfall rate and radar reflectivity. Atmospheric Measurement Techniques 6, 36353648. doi:10.5194/amt-6-3635-2013.

Wood, N.B., L'Ecuyer, T.S., Heymsfield, A.J., Stephens, G.L., 2015. Microphysical constraints on millimeter-wavelength scattering properties of snow particles. Journal of Applied Meteorology and Climatology 54, 909-931. doi:10.1175/JAMC-D-14-0137.1.

Wood, N.B., L'Ecuyer, T.S., Heymsfield, A.J., Stephens, G.L., Hudak, D.R., Rodriguez, P., 2014. Estimating snow microphysical properties using collocated multisensor observations. Journal of Geophysical Research Atmospheres 119, 8941-8961. doi 10.1002/2013JD021303.

Yang, D., Elomaa, E., Tuominen, A., Aaltonen, A., Goodison, B., Gunther, T., Golubev, V., Sevruk, B., Madsen, H., Milkovic, J., 1999. Wind-induced Precipitation Undercatch of the Hellmann Gauges. Nordic Hydrology 30, $57-80$. 
Zawadzki, I., Jung, E., Lee, G., 2010. Snow Studies. Part I: A Study of Natural Variability of Snow Terminal Velocity. Journal of the Atmospheric Sciences 67, 1591-1604. doi $10.1175 / 2010 J A S 3342.1$

Zhang, G., Luchs, S., Ryzhkov, A., Xue, M., Ryzhkova, L., Cao, Q., 2011. Winter precipitation microphysics characterized by polarimetric radar and video disdrometer observations in central Oklahoma. Journal of Applied Meteorology and Climatology 50, 1558-1570. doi 10.1175/2011JAMC2343.1 